
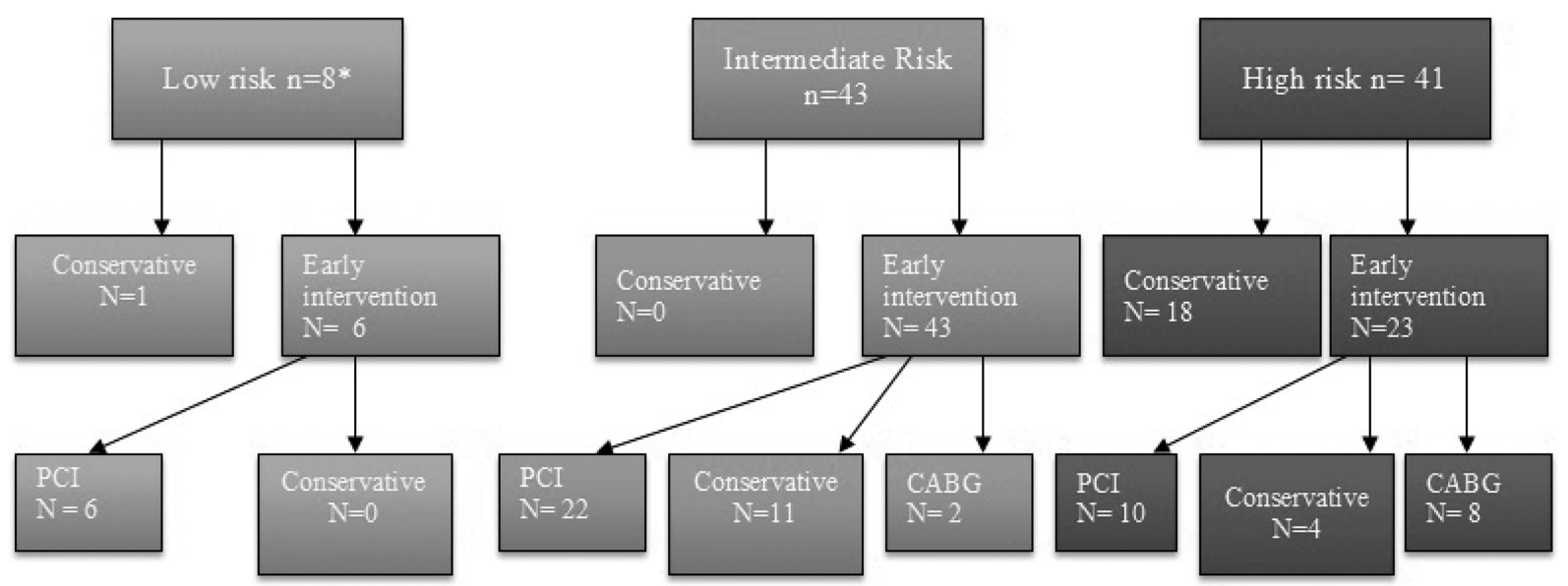

$\mathrm{PCI}=$ percutaneous coronary intervention
$\mathrm{CABG}=$ Coronary artery bypass graft
Conservative=Conservative management
*1 Patient Lost to follow up

Abstract 104 Figure 2 Outcome if Invasive Management group: Those stratified for inpatient angiogram/PCI

were on average 20 years older than those in lower risk. They were also frailer, and because of co-morbidities were more likely to wait longer for their PCI, or be managed conservatively. With such an age-related bias, this questions how the GRACE score should be used in management pathways when a high proportion of patients do not qualify for the recommended treatment options. Perhaps other tools are needed for the categorisation of ACS patients to identify the true high-risk population who benefit from early intervention; or inclusion of a frailty index to reflect the complex needs of an increasingly elderly population?

\begin{tabular}{|c|c|c|c|}
\hline & $\begin{array}{l}\text { Low } \\
\text { risk } \\
n=8\end{array}$ & $\begin{array}{l}\text { Intermediate } \\
\text { risk } n=43\end{array}$ & High risk $n=41$ \\
\hline Age & $63 \pm 8$ & $64 \pm 13$ & $\begin{array}{l}81 \pm 11(\mathrm{P}<0.001 \\
\text { intermediate +low risk vs } \\
\text { high) }\end{array}$ \\
\hline ECG changes & $\begin{array}{l}6 \\
(75 \%)\end{array}$ & $22(51.2 \%)$ & $22(53.4 \%)$ \\
\hline Troponin rise & $\begin{array}{l}4 \\
(50 \%)\end{array}$ & $43(100 \%)$ & $34(83 \%)$ \\
\hline Creatinine (umol/l) & $\begin{array}{l}76.8 \pm \\
18.5\end{array}$ & $105.72 \pm 62.3$ & $\begin{array}{l}127.65 \pm 63.1(p= \\
0.0467 \text { intermediate +low } \\
\text { risk vs high) }\end{array}$ \\
\hline Length of stay (days) & $\begin{array}{l}3.5 \pm \\
1.0\end{array}$ & $6.2 \pm 7.4$ & $\begin{array}{l}9.6 \pm 8.6(p=0.022 \\
\text { intermediate +low risk vs } \\
\text { high) }\end{array}$ \\
\hline $\begin{array}{l}\text { Cath }<24 \mathrm{~h}^{* *} \text { (as a percentage of } \\
\text { those allocated for invasive } \\
\text { management) }\end{array}$ & $\begin{array}{l}2 \\
(2.9 \%)\end{array}$ & $18(26.1 \%)$ & $6(8.7 \%)$ \\
\hline Cath $24-48 \mathrm{~h}^{* *}$ & $\begin{array}{l}3 \\
(4.3 \%)\end{array}$ & $15(21.7 \%)$ & $8(11.6 \%)$ \\
\hline Cath $>72 \mathrm{~h}^{* *}$ & $\begin{array}{l}1 \\
(1.4 \%)\end{array}$ & $7(10.1 \%)$ & $9(13.0 \%)$ \\
\hline Medical Management & $\begin{array}{l}1 \\
(12.5 \%)\end{array}$ & $0(0 \%)$ & $18(44 \%)$ \\
\hline
\end{tabular}

\section{IMPACT OF CV RISK FACTORS/DISEASE ON LENGTH OF STAY AND MORTALITY IN PATIENTS PRESENTING WITH MI}

${ }^{1}$ Brodie L Loudon*, ${ }^{1}$ Nicholas D Gollop, ${ }^{2}$ Paul R Carter, ${ }^{3}$ Hardeep Uppale, ${ }^{4}$ Jaydeep Sarma, ${ }^{5}$ Suresh Chandran, ${ }^{3}$ Rahul Potluri. ${ }^{1}$ University of East Anglia; ${ }^{2}$ Royal Free London NHS Trust; ${ }^{3}$ Aston University Birmingham; ${ }^{4}$ University Hospital South Manchester; ${ }^{5}$ North Western Deanery, Manchester; *Presenting Author

\subsection{6/heartjnl-2016-309890.105}

Background Classical risk factors for cardiovascular disease such as hypertension and diabetes, and their association with myocardial infarction (MI), have been thoroughly investigated. However, more research is needed to investigate the correlation between these risk factors and the impact on length of stay (LOS) and mortality in patients presenting with MI, which was the aim of this study.

Methods We reviewed anonymous patient data including demographics, LOS, prevalence of cardiovascular comorbidities, and mortality during 25,287 consecutive admissions for MI from seven hospitals in the North West of England between 1 January 2000 and 31 March 2013. The ACALM (Algorithm for Comorbidities, Associations, Length of stay and Mortality) protocol, using ICD-10 and OPCS-4 coding systems, was used to track patient data. LOS and mortality of MI patients with and without cardiovascular comorbidities was compared by multinomial logistic regression. $\mathrm{P}$ values $<0.05$ were taken as statistically significant.

Results Of 25,287 patients admitted with MI over the study period, mean $( \pm$ SD) age was $66.6 \pm 14.3$ and $64.2 \%$ were male. The mean $( \pm \mathrm{SD})$ LOS was $7.0 \pm 16.2$ days and there were a total of $9,653(38.2 \%)$ deaths. The classical cardiovascular risk factors hypertension and hyperlipidaemia were associated with a decreased LOS and mortality (7.0 and 4.8 days respectively, $\mathrm{P}<0.001 ; 36.8 \%$ OR 0.72 [95\% CI $0.67-0.77$ ] and $19.4 \%$ OR 0.42 [95\% CI $0.39-0.46$ ] respectively, $\mathrm{P}<$ 0.001 ), whereas diabetes was associated with a longer LOS and higher mortality (7.8 days, $\mathrm{P}<0.05 ; 44.4 \%$ OR 1.3 [95\% CI 1.20-1.41], P $<0.001)$. Angina pectoris was associated with shorter LOS and reduced mortality (5.4 days; $33.5 \%$ OR 0.75 [95\% CI 0.68-0.82], P $<0.001)$. Other 
Abstract 105 Table 1 Characteristics of patients presenting with ACS

\begin{tabular}{ll} 
Demographics & $\mathrm{n}=25,287$ \\
\hline Mean age (years) & $66.6(14.3)$ \\
Male & $16,227(64.2 \%)$ \\
Female & $9060(35.8 \%)$ \\
Ethnicity & \\
Caucasian & $20,302(80.3 \%)$ \\
South Asian & $1622(6.4 \%)$ \\
Afro-Caribbean & $197(0.8 \%)$ \\
Oriental & $51(0.2 \%)$ \\
Mixed & $48(0.2 \%)$ \\
Other & $357(1.4 \%)$ \\
Unknown & $2710(10.7 \%)$ \\
Mean LoS (days) & $7(16.2)$ \\
Deaths & $9653(38.2 \%)$ \\
\hline Data are number (\%) or mean (SD).
\end{tabular}

concomitant cardiovascular diseases were associated with an increased LOS and mortality: PVD (8.6 days, $\mathrm{P}<0.05 ; 53 \%$ OR 1.93 [95\% CI 1.68-2.21], P < 0.001), AF (10.9 days;
63.5\% OR 1.51 [95\% CI 1.38-1.66], P < 0.001), Cerebrovascular disease $(15.9$ days; $76 \%$ OR 2.29 [95\% CI $1.67-$ 3.15], $\mathrm{P}<0.001)$, HF (11 days; 69.9\% OR 3.28 [95\% CI 3.03-3.56], $\mathrm{P}<0.001)$, and IHD (6.7 days, $\mathrm{P}<0.001$; $38.7 \%$ OR 1.16 [95\% CI 1.06-1.26], P < 0.05).

Conclusion Cardiovascular risk factors and concomitant disease have a significant impact on LOS and mortality in patients presenting with MI. The presence of these diseases should be used to identify patients at an increased risk of prolonged admissions and death post MI, and services should be directed accordingly.

\section{Interventional Cardiology}

\section{CARDIOVASCULAR DISEASE OUTCOMES STRATEGY DRIVES IMPROVED SURVIVAL FOR PATIENTS WITH OUT- OF-HOSPITAL CARDIAC ARREST}

Shona Johnson*, Stephanie Horne, Tracey Realey, Liza Keating, William Orr. Royal Berkshire Hospital; *Presenting Author

\subsection{6/heartjnl-2016-309890.106}

Background NHS statistics show that Emergency Medical Services (EMS) attend nearly 60000 patients with out-of-hospital cardiac arrest (OOHCA) in England each year and attempt cardiopulmonary resuscitation (CPR) in approximately 28000 cases. The chances of survival are improved by an immediate call for help, early bystander CPR and defibrillation, rapid

\begin{tabular}{|c|c|c|c|c|c|}
\hline $\begin{array}{l}\text { Cardiovascular } \\
\text { Disease/Risk } \\
\text { Factors }\end{array}$ & $N(\%)$ & $\begin{array}{l}\text { Mean } \\
\text { Los } \\
\text { (days) }\end{array}$ & $\begin{array}{c}\text { ODDs ratio for Length } \\
\text { of stay }\end{array}$ & $\begin{array}{c}\text { Crude number } \\
\text { of deaths } \\
\text { (\% mortality) }\end{array}$ & $\begin{array}{l}\text { ODDs ratio for } \\
\text { mortality post } \mathrm{AMI}^{2}\end{array}$ \\
\hline Hypertension & $\begin{array}{r}11,393 \\
(45.1)\end{array}$ & 7.0 & $0.997^{\ddagger}(0.995-0.999)$ & $4197(36.8)$ & $0.717^{\ddagger}(0.671-0.765)$ \\
\hline Hyperlipidaemia & $\begin{array}{r}6274 \\
(24.8)\end{array}$ & 4.8 & $0.982^{\ddagger}(0.979-0.985)$ & $1214(19.4)$ & $0.423^{\ddagger}(0.390-0.459)$ \\
\hline T2DM & $\begin{array}{r}4758 \\
(18.8)\end{array}$ & 7.8 & $1.003^{*}(1.001-1.004)$ & $2112(44.4)$ & $1.304^{\ddagger}(1.204-1.411)$ \\
\hline T1DM & $698(2.8)$ & 7.0 & $1.001(0.998-1.005)$ & $288(41.3)$ & $1.674^{\ddagger}(1.396-2.007)$ \\
\hline Angina & $\begin{array}{r}8079 \\
(31.9)\end{array}$ & 5.4 & $0.983^{\ddagger}(0.980-0.985)$ & $2705(33.5)$ & $0.746^{\ddagger}(0.679-0.819)$ \\
\hline PVD & $1285(5.1)$ & 8.6 & $1.003^{*}(1.000-1.005)$ & $681(53.0)$ & $1.926^{*}(1.681-2.207)$ \\
\hline $\mathrm{AF}$ & $\begin{array}{r}3484 \\
(13.8)\end{array}$ & 10.9 & $1.008^{\ddagger}(1.006-1.010)$ & $2211(63.5)$ & $1.514^{\ddagger}(1.384-1.656)$ \\
\hline CVD & $1312(5.2)$ & 15.9 & $1.016^{\ddagger}(1.014-1.018)$ & $997(76.0)$ & $2.293^{\ddagger}(1.671-3.145)$ \\
\hline Heart Failure & $\begin{array}{r}4665 \\
(18.4)\end{array}$ & 11.0 & $1.012^{\ddagger}(1.010-1.015)$ & $3259(69.9)$ & $3.281^{\neq}(3.025-3.559)$ \\
\hline IHD & $\begin{array}{r}12,363 \\
(48.9)\end{array}$ & 6.7 & $0.996^{\ddagger}(0.994-0.998)$ & $4783(38.7)$ & $1.159 *(1.062-1.264)$ \\
\hline
\end{tabular}

T2DM, type 2 diabetes mellitus; T1DM, type 1 diabetes mellitus; PVD, peripheral vascular disease; AF, atrial fibrillation; CVD, cerebrovascular disease; IHD, ischaemic heart disease.

a Adjusted for age, sex, and ethnicity.

* Statistically significant, $\mathrm{p}<0.05$.

₹ Statistically significant, $p<0.001$. 